\title{
ENTRE O PÓDIO E O PICADEIRO: O SPORTSMAN CIRCENSE ZECA FLORIANO
}

\author{
Daniel de Carvalho Lopes ${ }^{1}$ \\ Mônica Caldas Ehrenberg ${ }^{2}$
}

\section{RESUMO}

No século XIX e início do XX, as artes circenses influenciaram as práticas ginásticas no Brasil ligadas a uma ideia científica de educação do corpo voltadas aos intuitos de controle, utilidade e desenvolvimento de hábitos higiênicos. Com objetivo de tratar dos entrelaçamentos históricos entre circo e Educação Física, analisamos a atuação de José Floriano Peixoto como sportsman, ginasta e artista circense e o quanto os saberes dos circenses estiveram promovendo diálogos entre tais campos.

Palavras-chave: história, educação, circo, educação física.

\footnotetext{
${ }^{1}$ Universidade de São Paulo (USP), São Paulo/SP, Brasil.

2 Universidade de São Paulo (USP), São Paulo/SP, Brasil.
} 


\title{
ENTRE EL PODIO Y EL PICADEIRO: EL SPORTSMAN CIRCENSE ZECA FLORIANO
}

\section{RESUMEN}

En el siglo XIX y principios del XX las artes circenses influenciaron las prácticas gimnásticas en Brasil ligadas a una idea científica de educación del cuerpo dirigidas a los propósitos de control, utilidad y desarrollo de hábitos higiénicos. Con el objetivo de tratar las mezclas históricas entre circo y Educación Física, analizamos la actuación del José Floriano como sportsman, gimnasta y artista circense y cuanto los saberes de los circenses estuvieron promoviendo diálogos entre tales campos.

Palabras clave: historia, educación, circo, educación física.

\section{BETWEEN THE PODIUM AND THE ARENA: THE CIRCUS SPORTSMAN ZECA FLORIANO}

\begin{abstract}
During the 19th century and early 20th century, the circus influenced the gymnastics practices in Brazil connected to a scientific idea of body education linked to the purpose of control, utility and development of hygiene habit. With the goal of approach the historical mixtures between circus and physical education, we analyzed the acting of the José Floriano Peixoto as sportsman, gymnast and circus artist and how much the circus knowledge were promoting the dialogues between those areas.
\end{abstract}

Keywords: history, education, circus, physical education.

\section{ENTRE LE PODIUM ET LA PISTE: LE SPORTSMAN DU CIRQUE ZECA FLORIANO}

\section{RÉSUMÉ}

Au XIXe et au début du XXe siècle, l'art du cirque ont influencé les pratiques de gymnastique au Brésil liées à une idée scientifique de l'éducation corporelle visant à contrôler, à utiliser et habitudes hygiéniques. Afin de traiter des mélanges historiques entre le cirque et l'éducation physique, nous avons analysé la performance de José Floriano Peixoto en tant que sportif, gymnaste et artiste et la mesure dans laquelle les connaissances du cirque ont favorisé les dialogues entre ces domaines.

Mots-clés: histoire, éducation, le cirque, éducation physique. 


\section{INTRODUÇÃO}

No decorrer do século XIX e início do XX, o circo foi um dos pioneiros e principais espaços de difusão de imagens e informações sobre as práticas ginásticas, mesmo que questionado e combatido por parte daqueles que defendiam uma ideia científica de educação do corpo ligada aos intuitos de controle, disciplina, utilidade e desenvolvimento de hábitos higiênicos (SOARES, 2005; MELO e PERES, 2014).

Nesse sentido, pretendemos tratar dos entrelaçamentos históricos entre as artes circenses e a ginástica no Brasil no início do século XX, tendo como objetivo evidenciar os saberes dos circenses no que tange ao corpo e à produção do espetáculo e destacar o quanto os circenses foram detentores de múltiplos conhecimentos e práticas ligados ao corpo decorrentes da elaboração e fazer de sua própria arte (SILVA, 2007; 2009).

Assim, em busca de compreendermos como e por quais razões circo e ginástica estruturaram-se como áreas que se misturaram e se confrontaram, analisamos parte da intensa atuação do atleta José Floriano Peixoto como sportsman, professor de ginástica, artista e diretor circense no início do século $\mathrm{XX}$.

Diante dessa proposta de análise, realizamos o levantamento, seleção e cruzamento de diferentes fontes (CERTEAU, 2010), constituindo um corpo documental composto por livros, artigos, iconografias e, principalmente, 20 diferentes títulos de jornais e revistas de quatro Estados brasileiros (São Paulo, Rio de Janeiro, Pernambuco e Paraíba). Destes periódicos, consultados na Hemeroteca Digital da Biblioteca Nacional (RJ), obtivemos aproximadamente 461 ocorrências referentes à atuação de José Floriano Peixoto, portanto vinculadas ao um recorte temporal de 1887 até aproximadamente a década de 1970.

Por meio dos percursos de Zeca Floriano no âmbito da ginástica, do circo e do esporte no início do século XX, é possível compreender o quanto as 
práticas corporais circenses e às ligadas à ginástica, aos esportes e à educação do corpo estiveram em permanente mistura e diálogo, entrelaçadas e conjugadas seja através da espetacularização das mesmas e do picadeiro como espaço que as fundia, seja pela semelhança das ações corporais que assumiam.

\section{O SPORTSMAN}

José Floriano Peixoto, nascido em 05 de agosto de 1887, era o caçula dos filhos homens de Josina Vieira Peixoto e do Marechal Floriano Peixoto, presidente do Brasil de 1891 a 1894. Zeca Floriano, como era conhecido, foi um dos atletas mais populares e referenciados no início do século XX, sendo considerado um dos primeiros homens no Rio de Janeiro a exibir um modelo de corpo forte e musculoso numa época em que o tipo físico valorizado era justamente o oposto (MELO, 2007a). Um exemplo desse reconhecimento de Zeca Floriano aparece na Revista de Theatro e Sport (1921, p. 9), que além de orgulhosamente publicar em sua capa uma foto do atleta, exaltou suas qualidades ao afirmar que ele aliava "invejável força muscular" às qualidades de "perfeito cavalheiro", o que o tornava o "mais querido e respeitado dos atletas brasileiros" e "a maior e legítima glória do nosso atletismo".

Não é sem motivo o teor das referências ao atleta, uma vez que Peixoto foi praticante medalhista em cerca de dezoito modalidades esportivas como boxe, luta romana, tiro ao alvo, remo, halterofilismo, natação, futebol, atletismo e ginástica, além de ter realizado o feito heroico de salvar cerca de 80 pessoas em um naufrágio que ocorrera em Salvador, Bahia, no dia 04 de março de 1911 (O PAIZ, 23/04/1911).

Zeca, simultaneamente à sua profícua atuação como sportsman, obteve também destaque como artista de circo, tendo abandonado a Academia Militar para trabalhar em espetáculos variados e, posteriormente, empresariar seu próprio circo, o Circo Floriano (NASCIMENTO, 2015). 
No campo dos esportes, são várias as experiências e títulos conquistados por Zeca Floriano. Nos primeiros anos do século XX, contamos com diversos informes publicados nos jornais fluminenses referentes à sua participação em campeonatos, clubes e eventos em várias modalidades, mas principalmente na modalidade de Remo, a exemplo da disputa de um Campeonato de Remo como amador da equipe Clube de Regatas Boqueirão do Passeio (GAZETA DE NOTÍCIAS, 24/10/1904, p. 4).

Nesse Clube, José Floriano participou também de aulas de ginástica realizadas em função das comemorações de aniversário do Clube Boqueirão (O PAIZ, 21/04/1905). A presença do sportsman nessas aulas e o fato de ter frequentado o Colégio Militar explicitam que parte da instrução de Floriano residiu no campo das práticas ginásticas e corporais institucionalizadas, ou seja, racionalizada, de cunho higienista, militar e cientificista em voga neste período (GOELNER, 1992; SOARES, 2001, VIGARELLO, 2003; GÓIS JUNIOR, 2013), sendo que esta instrução se soma e se mistura com sua também formação e atuação como artista circense e empresário e diretor de circo.

Ainda em sua extensa atuação no campo dos esportes e da ginástica, Zeca Floriano também foi responsável pela fundação e direção de Clubes, a exemplo do Clube Esportivo S. Cristóvão, destinado a ensinar e oferecer as práticas de "futebol, corridas a pé, luta romana, ginástica e esgrima" (GAZETA DE NOTÍCIAS, 29/09/1905, p. 3). Na comemoração de um ano de suas atividades, o Clube contou com a "apresentação de soberba aula de ginástica magistralmente dirigida pelo Sr. José Floriano Peixoto" (GAZETA DE NOTÍCIAS, 21/04/1906, p. 5), o que evidencia sua inclinação para a promoção e orientação em Educação Física e, consequentemente, a imersão de Floriano no campo da ginástica não apenas como praticante, mas como professor.

A ênfase que temos dado ao desempenho do atleta no campo da ginástica, como discorreremos mais adiante, se deve ao fato de que Floriano dedicou-se com empenho também às artes circenses e ao espetáculo em geral, campos cujas práticas corporais eram criticadas e desqualificadas por aqueles 
que atuavam com uma educação do corpo sedimentada, no período, pela terminologia e amplo conceito de ginástica em diversas instituições médicas, escolares, militares e associativas (SOARES, 2001; SILVA, 2007, GÓIS JUNIOR e HAUFFE, 2014; MELO e PEREZ, 2014).

Possivelmente em função da experiência de Floriano como presidente do Clube Esportivo S. Cristóvão, o mesmo passou a presidir também o clube de atletismo denominado Esporte Clube José Floriano (O PAIZ, 29/05/1907), o qual, além da promoção de variadas disputas esportivas, oferecia aos seus sócios "modernos aparelhos para se exercitarem no higiênico esporte de ginástica e outros exercícios” (O PAIZ, 20/06/1907, p. 5), dos quais, vale destacar, o "grande aparelho mestre, de que faz parte o trapézio, argolas e trampolim" (GAZETA DE NOTÍCIAS, 26/05/1911, p. 6). A respeito dessas aparelhagens do clube, é importante frisar que foram constituídas por equipamentos idênticos aos encontrados nos espetáculos circenses, aos que compuseram os ginásios destinados à prática de exercícios ginásticos em fins do século XVIII e início do XIX na Europa, e aos presentes em escolas e clubes ginásticos no Brasil a partir dos anos de mil e oitocentos (MELO e PERES, 2014; ROMÃO, 2016). Em função disso, Zeca Floriano, já nesse período trabalhando no universo do circo e dos espetáculos de variedades, incorporou à sua atuação como ginasta e, principalmente, como professor de ginástica, os saberes, técnicas e práticas circenses.

Ainda, em meio ao envolvimento de Zeca Floriano na gestão de clubes e associações esportivas, contamos com uma nota que informa a intenção do atleta de fundar uma escola de Educação Física voltada para o ensino de ginástica, acrobacia, atletismo e lutas (GAZETA DE NOTÍCIAS, 16/01/1909). Apesar de não termos a confirmação da realização desse empreendimento do ano de 1909, sabemos que Floriano fundou em 1915 a "Escola Atlética Modelo José Floriano Peixoto", composta por uma "higiênica sala e completo aparelhamento" e comprometida com o "desenvolvimento físico dos filhos do nosso Brasil” (O PAIZ, 27/o1/1915, p. 6). 
Com isso, conforme apresentamos até o momento, Zeca Floriano atuou como atleta e professor de ginástica e modalidades esportivas e, também, na direção de espaços voltados para o ensino e prática de Educação Física3. Assim, mesmo sendo intenso e significativo seu trabalho no campo da ginástica e do esporte, Zeca, simultaneamente à sua carreira como esportista, ginasta, educador e empreendedor, misturou-se com o universo dos espetáculos ao protagonizar demonstrações competitivas e espetaculares de Luta Romana, realizar feitos de coragem e se apresentar como ginasta e acrobata em diferentes palcos e, claro, no seu próprio circo.

\section{O MARECHAL DO CIRCO ${ }^{4}$}

Já no início dos anos de 1900, ou seja, no começo de sua carreira no campo do esporte, o atleta estava envolvido no grupo de apresentações de Paul Pons, francês conhecido por Colosso e campeão mundial de luta Greco-romana, que contribuiu consideravelmente nos primórdios do halterofilismo no Brasil (RIBEIRO, 2015).

Após conquistar o primeiro lugar no Campeonato Nacional de Luta Romana, no Politeama de São Paulo, Zeca Floriano, em demonstração de coragem, protagonizou um "espetáculo bem curioso e que também não deixa de ser sensacional" (CORREIO PAULISTANO, 04/04/1909, p. 3) ao entrar na jaula do "monstruoso leão Marrusko", que estava exposto na capital paulista, cujo proprietário ofereceu dez contos de réis a quem realizasse o feito.

Em seguida à realização dessas exibições, enfrentou no Concerto

\footnotetext{
3 Zeca Floriano fundou também a Sociedade Esportiva Sete de Setembro, em Maceió, Alagoas. Em 1914 esta Sociedade organizou um clube de futebol que recebeu a denominação de José Floriano Futebol Clube (O PAIZ, 15/05/1914).

4 A denominação de Zeca Floriano como "O Marechal do Circo" foi adotada em extensa matéria sobre ele publicada na edição de 233 da revista A Cigarra, 01 de agosto de 1953, a qual apresenta diversas fotos do atleta/artista e as seguintes manchetes: "O Marechal do Circo: Filho de José Floriano Peixoto, artista de circo - Campeão de todos os esportes", "José Floriano Peixoto Filho trocou a vida do palácio pelo picadeiro. Preferiu o circo à vida fácil do paço" e "A Espada do Pai, os músculos do filho" (A CIGARRA, 01/o8/1953, p. 9).
} 
Avenida, empresa gerida pelo empresário do ramo de divertimentos Paschoal Segreto, o "selvagem lutador alemão Scharmann", em "grandioso espetáculo realizado em benefício do jornal A Imprensa Esportiva", semanário de esportes de direção e propriedade do também sportsman Rosendal, no qual se sagrou vencedor (GAZETA DE NOTÍCIAS, 29/09/1909, p. 8). No ano seguinte, Zeca Floriano, em parceria com o empresário paulista Francisco Serrador, organizou um campeonato de luta romana para mulheres, realizado no Teatro São Pedro de Alcântara, e que, na realidade, consistia numa temporada teatral em conjunto com o grupo musical feminino Mirales (MELO, 2007b).

Dentre as várias lutas-espetáculo disputadas, vale destacar aquela cumprida no Palace Theatre divulgada como "um grandioso espetáculo de variedade", em 1911, em que o "campeão austríaco George Rihsbacher" desafiou o "campeão amador brasileiro José Floriano Peixoto", espetáculo no qual estrearam os "afamados artistas Darbon - Nodart, duetistas franceses" (O PAIZ, 18/o9/1911, p. 10). Vale ressaltar também, em 1913, "O Grande Campeonato Sul Americano de Luta Romana, o espetáculo mais sensacional desta temporada", realizado no Teatro São José, que, além da exibição das lutas protagonizadas por Zeca Floriano e adversários, tomaram parte também "Os Stevens, notáveis atiradores; Sônia, notável trapezista; Cezar e Alfred, equilibristas de força" e "Bruno Stefano, canções napolitanas" (CORREIO PAULISTANO, 09/11/1913, p. 11).

É importante observar que, além dessas lutas comporem espetáculos de variedades, os seus anúncios e propagandas se assemelhavam com os dos espetáculos circenses divulgados no período, trazendo da mesma forma dizeres acalorados e aclamativos, e solicitando a assistência do público ao "mais grandioso espetáculo da atualidade" (O PAIZ, 16/09/1911, p. 16). Assim, não por acaso, as propagandas dessas lutas-espetáculo figuravam ao lado das propagandas circenses, a exemplo das lutas de Zeca Floriano com o austríaco Koenen (O PAIZ, 07/09/1911, p. 12) e Zeca Floriano e Rihsbacher (O PAIZ, 16/09/1911, p. 11), que dividiam espaço com propagandas do Circo Spinelli, 
"Companhia Equestre Nacional da Capital Federal" de propriedade do trapezista e palhaço Affonso Spinelli e sob direção artística do aclamado artista Benjamim de Oliveira (O PAIZ, 07/09/1911, p. 12).

Em função da inclinação de Floriano ao espetáculo, a aproximação com o Circo Spinelli não residiu apenas nas páginas de jornal. Durante o evento de premiação destinada aos alunos classificados nos exames finais do Centro Cívico Sete de Setembro, também dirigido por Floriano, em janeiro de 1913, foram prestadas homenagens não somente ao sportsman, mas ao Centro de Cultura Física do Rio de Janeiro, à imprensa fluminense e à "grande companhia do Spinelli” (O PAIZ, 01/01/1913, p. 5). Isso, de certa maneira, evidencia que Floriano já nesse início de 1913 possuía contato com esses circenses e que, possivelmente, já os conhecia desde 1911, quando estiveram atuando no mesmo período no Rio de Janeiro.

E, realmente, o contato direto de Floriano com a Companhia do Spinelli se concretizou, dentre outras maneiras, com a realização da "festa artística em benefício da escola noturna gratuita do Centro Cívico Sete de Setembro", sediada no próprio Circo (O PAIZ, 23/12/1913, p. 4).

\section{Circo Spinelli}

Realiza-se hoje o festival que terá lugar no circo Spinelli, em benefício da escola noturna gratuita do Centro Cívico Sete de Setembro. Nesta festa de arte tomará parte o grande campeão brasileiro José Floriano Peixoto, que se apresentará com seu dolman preto, ostentando grande número de medalhas que lhe tem sido ofertadas nas grandes lutas esportivas, pelo poder da força.

Nessa ocasião o conhecido sportsman inaugurará as aulas de educação física do Centro Cívico, das quais é diretor, sendo em seguida realizado o ato solene de entrega, ao referido campeão, de uma medalha de ouro, artisticamente trabalhada pela casa Umberto Adamo, contendo a seguinte inscrição: "A José Floriano Peixoto - Culto do Centro Cívico Sete de Setembro".

O Exímio barrista Gustavo, professor de ginástica do centro, dará a sua estreia pública em conjunto com os alunos Bastos, Jayme e Philemon, no assombroso trabalho em tríplice barra, com os olhos vendados. A diretoria e grande comissão de alunos do centro tomarão 
parte no ato da inauguração, realizando-se depois, várias surpresas de agradecimento público.

Tocará no jardim do circo, que estará feericamente iluminado, além da banda musical da companhia, outras cedidas pelas forças de mar e terra.

Toda a Companhia Spinelli abrilhantará o festival, com trabalhos dignos de encômios (O PAIZ, 26/12/1913, p. 2).

Após essa entrada de Zeca no circo de Affonso Spinelli, o atleta atuou em pelo menos mais um de seus espetáculos, apresentando uma disputa de luta romana:

\section{LUTA ROMANA}

Conforme anunciado, realizou-se anteontem a importante luta entre o conhecido e popular campeão brasileiro José Floriano Peixoto e o atleta italiano Segatto. O encontro teve lugar no Circo Spinelli, cuja companhia tomou parte da festa, para maior brilhantismo, havendo excelentes números pelos irmãos Pery e Canalles, sendo que estes últimos efetuaram trabalhos novos em os seus afamados cavalos.

Antes da luta, os irmãos Pery, com a interessante "charge" denominada "Uma tourada", fizeram reinar intensa alegria entre os assistentes.

Às 10 Horas em ponto, depois de maviosa marcha executada pela significativa banda Spinelli, deram entrada no picadeiro os lutadores, fazendo-se ouvir estrondosa salva de palmas, saudando o invencível Zeca Floriano. A seguir, foi começada a luta, saindo vencedor o referido campeão brasileiro. No último golpe, o público não se conteve, fazendo o público uma manifestação à Floriano (O PAIZ, 28/01/1914, p. 7).

Por meio das notas apresentadas acima, Zeca Floriano apresentou-se no picadeiro de Afonso Spinelli com a exibição de suas lutas e outras realizações no campo da Educação Física, em especial, por meio das aulas e demonstrações de ginástica, protagonizadas pelos membros do Centro Cívico Sete de Setembro. Dessa aproximação do sportsman com a companhia, vários aspectos merecem ser destacados e analisados.

Em primeiro plano, chama-nos a atenção o fato do Centro Cívico 
dirigido por Floriano, voltado especificamente para o ensino e desenvolvimento de atividades ginásticas e esportivas, prestar homenagens, numa mesma cerimônia, a duas instituições teoricamente díspares e divergentes na perspectiva dos sentidos atrelados às práticas ginásticas e acrobáticas que desenvolviam, como é o caso da Grande Companhia do Spinelli e do Centro de Cultura Física do Rio de Janeiro. Nesse sentido, a homenagem prestada coloca em proximidade duas instituições que, em certa medida, possuíam suas práticas corporais orientadas por valores, saberes e métodos diferenciados e que acarretavam em divergências assumidas por parte dos representantes da ginástica institucionalizada, imbuída de teor moralizante e de orientação científica e médico-higienista com relação às práticas corporais circenses (SOARES, 2005; GÓIS JUNIOR e HAUFFE, 2014).

Outro aspecto importante a ser ressaltado é tanto a inauguração das aulas de Educação Física do Centro Cívico Sete de Setembro realizadas num espetáculo circense, como a exibição integrada dos ginastas deste mesmo Centro com os artistas da Companhia, efetuada no próprio picadeiro do Spinelli. E, claro, somado a isso, o fato das exibições protagonizadas pelos ginastas do Centro apresentarem uma faceta extremamente espetacular e semelhante aos números circenses, posto que realizaram o "assombroso trabalho em tríplice barra, com os olhos vendados" (O PAIZ, 26/12/1913, p. 2).

A esse respeito, vale apontar que o discurso da ginástica ao longo do século XIX, tanto na Europa como no Brasil, criticava, entre outros aspectos, justamente a intencionalidade espetacular do circo e de suas ações e seu compromisso com o divertimento. Essa negação se dava em função da compreensão que tinham os pensadores e sistematizadores da ginástica científica da época sobre a utilização do corpo no circo, entendido apenas como simples espetáculo, pois além de não esboçar utilidade nos gestos, revelava gasto excessivo de energia. Assim, a compreensão que os defensores da ginástica possuíam era fruto de certa ideologia e concepção de mundo, em particular da burguesia que a respaldava, para os quais a "atividade física fora do mundo do 
trabalho deveria ser útil ao trabalho" (SOARES, 2005, p. 24). Com isso, o que estava fundamentando o pensamento e projeto desses grupos era a ideia de se preparar o corpo do homem trabalhador e do homem militar nos preceitos da ciência e, para tanto, seria necessário que as pessoas se inteirassem e fossem preparadas dentro das concepções, já desenvolvidas na Europa naquele período, da Educação Física científica.

No entanto, apesar da constante negação dos idealizadores e defensores de uma ginástica científica às expressões circenses, principalmente ao seu caráter de espetáculo, é importante mencionar que ela própria desenvolveu características de espetáculo para sua consolidação e divulgação na sociedade da época. É possível encontrar nos manuais e compêndios de ginástica do século XIX a negação sistemática dos elementos cênicos, funambulescos e acrobáticos, e um discurso contrário ao universo do circo e das festas populares e à corporeidade que compunham essas manifestações, mas, apesar disso, "é a ginástica científica que se oferece como espetáculo 'controlado' dos usos do corpo, um espetáculo protegido e trazido para adentro das instituições” (SOARES, 2005, p. 25). Se por um lado o caráter espetacular do corpo do circense era condenado por aqueles partidários da ginástica, por outro era frequente a realização de exibições ginásticas públicas e privadas por alunos de escolas, clubes e ginásios nesse período.

Nesse sentido, em especial a ginástica francesa foi uma das sistematizações de educação do corpo que evidenciaram a negação ao universo do circo e, ao mesmo tempo, expôs contradições entre seu discurso e sua prática. Os estudos e ideias do coronel Francisco Amoros (1838), que posteriormente foram organizados como método francês de ginástica, evidenciavam a mentalidade contrária ao circo e aos divertimentos, pois Amoros, apesar de admitir a prática de uma ginástica funambulesca, considerava que nela o fim nobre da ginástica era sacrificado ao frívolo prazer de distrair, tornando-a um espetáculo, e que o funambulismo começava quando findava a utilidade do exercício (GÓIS JUNIOR e HAUFFE, 2014). 
No Brasil, ideais similarmente contrários e combativos às práticas corporais circenses manifestaram-se de diferentes maneiras. Educadores, políticos, jornalistas e militares do final do século XIX ao início do XX exteriorizaram reações ofensivas ao circo e suas práticas, bem como à atuação de circenses como mestres de ginástica em escolas e clubes. Dentre eles, vale mencionar Arthur Higgins, mestre de ginástica em importantes instituições fluminenses na segunda metade do século XIX, que argumentava que a ginástica praticada nos circos tinha como finalidade "causar admiração pelo desapego à vida e da renda pecuniária. Essa ginástica, impropriamente chamada assim, repito, por ser prejudicial à saúde e muito perigosa, deve ser completamente banida dos estabelecimentos de educação" (HIGGINS, 1934, p. 24)5; e, também, o Deputado Jorge de Moraes, que em 1927 proferiu um discurso na Câmara dos Deputados do Rio de Janeiro denunciando que o ensino de ginástica estava a cargo de indivíduos exclusivamente técnicos, sem conhecimentos críticos, sendo em sua maioria egressos de circos, que desmoralizavam a importância da Educação Física (SILVA, 2009).

Posto isso, para além da entrada e apresentação no picadeiro do Spinelli dos ginastas do Centro Cívico dirigido por Floriano, incutidos de seus ideais de retidão, higiene, disciplina, utilidade e moral atrelados à prática da ginástica, é também o próprio ensino da ginástica que ocupou o picadeiro, pois na festa de arte promovida no Circo houve a inauguração das aulas de Educação Física do Centro, ou seja, foi promovido em um circo tanto a celebração a uma instituição voltada para a educação do corpo, como o ensino da ginástica.

Ademais, nessa espécie de cerimônia espetáculo, o professor de ginástica do Sete de Setembro realizou sua estreia pública em conjunto com seus alunos e, acerca desse fato, vale uma pergunta: estreia como professor ou artista circense? Se pretendermos uma resposta para essa questão, ela seria afirmativa para ambas as funções, pois o professor e seus alunos estavam em

\footnotetext{
5 Esta obra de Higgins é uma reedição ampliada e revisada feita pelo autor de seu "Compendio de Ginástica Escolar”, publicado em 1896.
} 
um circo, de frente para um público, celebrando a inauguração das aulas da instituição e, corroborando ainda mais, se exibindo no "assombroso trabalho em tríplice barra, com os olhos vendados" e realizando os exercícios/truques denominados "giro gigante" e "double-volta" (O PAIZ, 23/12/1913, p. 4).

Ainda, não podemos deixar de ressaltar que tanto na festividade do Sete de Setembro como na luta entre Floriano e Segatto, também realizada no picadeiro do Spinelli, a companhia do Circo se apresentou conjuntamente, "para maior brilhantismo" (O PAIZ, 28/01/1914, p. 7). Com isso, não restam muitos questionamentos do quanto a inauguração das aulas do Centro dirigido por Zeca Floriano e a peleja do mesmo com o atleta italiano Segatto, bem como as atrações apresentadas em ambas, tanto por parte dos ginastas do Centro como dos membros da companhia Spinelli foram evidentemente circenses.

Essas realizações explicitamente congregam, conjugam e fundem diretamente estes dois espaços, o Centro Cívico Sete de Setembro e o Circo, mas também suas práticas e saberes. E, como resultado desta combinação entre ginastas e circenses no centro de um picadeiro, as fronteiras entre a ginástica que se pretendia racionalizada, utilitária e metodizada e as evoluções corporais circenses se diluem a ponto de diretamente se fundirem e se entrelaçarem, explicitando a necessidade de pensar a ginástica no decorrer do século XIX e início do XX no plural ${ }^{6}$ e marcadamente influenciada por modelos, imagens e práticas do universo do circo.

Além de diluir fronteiras e solicitar um olhar para as ginásticas praticadas no referido período, esta junção de ginastas do Centro Cívico com a companhia do Circo Spinelli realçam características importantes da produção da linguagem circense.

Dentre essas características, destacamos um ponto crucial no que concerne à valorização do fato dos circenses serem detentores de saberes sobre o corpo, nem mais nem menos do que ginastas, médicos, professores de

\footnotetext{
6 Essa ideia é discutida por Gondra (2000), Soares (2001, 2005, 2009), Sant'Anna (2011), Melo e Peres (2014), entre outros.
} 
ginástica, militares, clubistas, atletas etc., mas, ao mesmo tempo, similares e diferentes, e ligados intimamente à própria produção de seus fazeres artísticos, sejam eles como trapezistas, malabaristas, contorcionistas, equilibristas, equestres, palhaços etc. Com isso, se por um lado, a própria imersão de Zeca Floriano no campo dos espetáculos explicitou a aproximação de ginastas e professores de ginástica com artistas circenses, tendo sido o picadeiro a sede desse encontro, por outro, o fato dos circenses serem detentores de importantes saberes e práticas no campo das ações corporais (sejam elas técnicas, de cuidado ou de treinamento) foi evidentemente o promotor e consolidador dessa mistura entre o universo do circo e o da ginástica institucionalizada, representada aqui mais especificamente pela atuação do Centro Cívico Sete de Setembro.

Em outras palavras, a junção de circenses e ginastas em meio ao picadeiro do Spinelli explicita o quanto os circenses possuíam conhecimentos importantes sobre diversas ações corporais e, em certa medida, evidencia também o seu reconhecimento por parte daqueles que atuavam no campo multifacetado da ginástica, com suas orientações disciplinadoras, higienista, cívica, moral, militar e respaldada no pensamento cientificista em voga no período.

Ademais, tomando por base a presença de ginastas e circenses atuando em um mesmo espetáculo, outra característica da produção da linguagem circense que salta aos olhos é a sua contemporaneidade, ou seja, os vários diálogos, incorporações e recriações, por parte dos circenses, dos aspectos culturais, artísticos, tecnológicos e políticos referentes ao período histórico no qual estão em interação (SILVA, 2007, 2009, 2016; LOPES, 2015). Dessa maneira, devido aos diversificados e permanentes vínculos que o circo estabelece com o período histórico em que se processa, o discurso da ginástica, seus sujeitos, espaços, práticas, disputas e tensões com o espetáculo não fugiram às suas incorporações e diálogos.

Apontados estes debates relacionados à mútua atuação de circenses e ginastas, retomamos à multifacetada atuação de Zeca Floriano que, além de sua 
participação no Circo Spinelli, trabalhou também em Petrópolis, no Coliseu Luso-Brasileiro, com uma companhia de variedades, em janeiro de 1915 (GAZETA DE NOTÍCIAS, 24/o1/15, p. 5), e no Cinema-Teatro Carlos Gomes, em um "Grandioso espetáculo de Variedades", efetuando suas disputas de luta e em parceria com os artistas "Conde Koma e sua afamada trupe de lutadores japoneses de Jiu-jítsu", "Les Fredonis, acrobatas cômicos sérios" e "Gallant, Hércules Mundial", exibindo a "prova de força humana" (O PAIZ, 04/05/1915, p. 14). Diretamente envolvido com o universo dos espetáculos e ligado intimamente ao campo das produções circenses, Zeca Floriano passou a dirigir seu próprio circo equestre e de variedades, ora denominado Pavilhão Floriano, ora Circo Floriano.

Dos trabalhos com seu circo, encontramos registros de suas apresentações tanto na cidade de São Paulo como no interior do Estado. Na capital paulista, o Pavilhão Floriano estreou, em fevereiro de 1916, "sendo todos os artistas aplaudidos" (CORREIO PAULISTANO, 14/o2/1916, p. 3). No mês de agosto, na cidade de Ribeirão Preto, a "grande companhia equestre e de variedades, sob direção do aplaudido atleta José Floriano Peixoto", efetuou espetáculos que lotaram seu "enorme pavilhão, cuja lotação é de cerca de 4000 pessoas", e nos quais destacou-se "o trio Floriano, nos sensacionais exercícios de força” (CORREIO PAULISTANO, 01/o8/16, p. 3).

Novamente no Rio de Janeiro no mês de novembro de 1917, a "Grande companhia ginástica, equestre e acrobática, dirigida por José Floriano Peixoto o melhor conjunto atualmente no Brasil” encabeçou espetáculos no Palace Theatre, que foi "convertido em circo, de forma a poderem apreciar-se todos os artistas da companhia" (O PAIZ, 30/11/1917, p. 4) e teve a sua estreia antecedida por uma "passeata alegórica pelo centro da cidade" realizada por toda a companhia (O PAIZ, 01/12/1917, p. 3). Posteriormente a esta atuação do Circo Floriano, já no início de 1918, Floriano iniciou uma nova série de exibições pelo estado de São Paulo, tendo chegado com seu circo na cidade paulista de Batatais em um trem especial (CORREIO PAULISTANO, 10/01/1920). 
Tomando por base as apresentações realizadas em agosto de 1916 em Ribeirão Preto, a temporada no Palace Theatre em novembro de 1917 e as exibições no Teatro República, podemos ressaltar importantes características tanto dos empreendimentos circenses do período como da empresa de Zeca Floriano.

Em Ribeirão Preto temos ideia da proporção do circo de Floriano quando informados de que seu pavilhão possuía lotação para 4000 pessoas, portanto, um estabelecimento de grandes dimensões. Além disso, outro aspecto estrutural da empresa de Zeca Floriano é a adaptabilidade de seu empreendimento a outros espaços, evidenciada por meio da conversão do Palace Theatre em circo. Tanto a grande estrutura de seu pavilhão quanto a execução de seu espetáculo em teatros transformados em circo são aspectos de ordem estrutural presentes no fazer circense desde a primeira metade do século XIX, a exemplo de companhias como o Pavilhão Universal de Albano Pereira, Circo Chiarini, Circo Olímpico da Guarda Velha e Circo Pery (LOPES, 2015; LOPES e SILVA, 2015), o que indica que Floriano empreendeu o seu circo tomando por base a experiência, logística e estrutura consolidadas pelos circenses há um considerável período no Brasil7.

Nesse sentido, outro exemplo interessante que ilustra essa incorporação dos saberes estruturais e organizacionais dos circenses por parte de Floriano é o fato do mesmo ter excursionado com seu circo no interior de São Paulo utilizando como meio de transporte um trem especial, possivelmente alugado pela companhia (CORREIO PAULISTANO, 10/01/1920). Ao longo de todo o século XIX e primeira metade do século $\mathrm{XX}$, diversas companhias circenses viajaram por meio do transporte ferroviário em todo o mundo, sendo que algumas delas, além de alugar linhas, vagões e locomotivas, chegaram a possuir seus próprios trens (RENEVEY, 1977; LOPES e SILVA, 2019). Com isso, vale destacar a complexidade dos saberes ligados ao processo organizacional e logístico dominado pelos circenses tanto para a criação e adaptação de espaços

7 A esse respeito, consultar: Avanzi e Tamaoki (2004), Silva (2007 e 2009) e Lopes (2015). 
para suas apresentações (circos de madeira, circos móveis, circos de alvenaria, pavilhões, teatros, galpões etc.) como para as viagens e transporte de todo o material e equipamentos da companhia por diversos países e continentes, que, como temos apresentado, foram de certa forma apreendidos por Zeca Floriano ao empresariar seu circo.

Assim, a possibilidade de Zeca Floriano ter incorporado experiências e saberes circenses para o desenvolvimento de sua empresa fica mais evidente quando o mesmo realizou uma passeata alegórica pelo centro do Rio de Janeiro para a divulgação da temporada de seu circo no Palace Theatre, uma vez que essa forma de propaganda é explicitamente utilizada pelos circenses desde finais do século XVIII (SILVA, 2007), além, principalmente, da presença em seu elenco de diversos artistas circenses pertencentes a famílias com larga experiência nas artes do circo. Em meio a palhaços, representações teatrais, acrobatas, excêntricos musicais, equilibristas, animais amestrados, acrobatas, equitadores, patinadores e uma vasta gama de diferentes artistas, figuraram no circo de Floriano circenses pertencentes às famílias Olimecha, François, Ozon, Temperani e Pery (O PAIZ, 27/07/21).

Dentre outros circenses que compuseram os espetáculos do circo de Floriano e com os quais ele possivelmente estabeleceu trocas e aprendizagens sobre os empreendimentos circenses, destacamos Benjamim de Oliveira, acrobata, cantor, compositor, ator, diretor, dançarino, músico, autor de peças e palhaço, com expressiva atuação em circos no final do século XIX e início do XX. Benjamim, como muitos outros circenses, foi um artista múltiplo, reconhecido para além das artes circenses, e figura importante para a consolidação do teatro no circo (SILVA, 2007). Floriano, possivelmente, já havia conhecido Benjamim em 1911, quando ambos atuaram no Rio de Janeiro no mesmo período, porém não em um mesmo espetáculo. No entanto, o contato direto entre os dois artistas possivelmente ocorreu em 1913, quando Floriano, em função da festa artística em benefício da escola do Centro Cívico Sete de Setembro, tanto prestou homenagem como atuou no picadeiro do Circo Spinelli, 
do qual Benjamim de Oliveira era diretor artístico (SILVA, 2007). Assim, decorrida essa aproximação prévia entre o sportsman artista e o palhaço, temos "Benjamim de Oliveira com seu violão" se apresentando no espetáculo do Pavilhão Floriano em 1921 (O PAIZ, 27/07/1921, p. 12) e, novamente, no Teatro Recreio, numa "grandiosa matinê" na qual Zeca também se apresentou (O PAIZ, 31/07/1921, p. 7).

O destaque que damos para a atuação conjunta de Floriano e Benjamim se deve não somente pelo argumento que temos construído de que Zeca atuou como artista e empresário de circo em contato direto com circenses experientes e destacados no período, o que nos leva a crer que Floriano muito aprendeu e trocou com esses artistas, mas também porque Benjamim de Oliveira pode ter sido uma figura que "estimulou" a entrada de Zeca no campo dos espetáculos circenses uma vez que o mesmo relata ter conhecido seu pai, o marechal Floriano Peixoto, conforme aborda as pesquisas de Erminia Silva (2007) e Daniel Marques da Silva (2004). É viável a ideia de que Zeca Floriano tenha entrado no meio circense incentivado pelo entusiasmo de seu pai pelo espetáculo e de sua possível aproximação com Benjamim de Oliveira e que, uma vez atuante nos ringues, palcos e picadeiros, tenha incorporado os mais diversos saberes circenses no que concerne a tudo o que se relaciona com produção do espetáculo e os conhecimentos técnicos, acrobáticos e corporais próprios dos artistas de circo.

Retornando à trajetória circense de Floriano, o sporstman artista estava com seu circo armado em junho de 1921 na Avenida Mem de Sá, Rio de Janeiro, e se uniu com a companhia equestre norte americana Nelky (O PAIZ, 09/08/1921), sendo tratado como o "grande circo que agora tem o campeão brasileiro José Floriano Peixoto" (O PAIZ, 17/11/1921, p. 5) e cabendo ao mesmo a organização e direção do espetáculo. Não somente com os Nelky que Floriano estabeleceu parcerias e montou apresentações em conjunto, prática comum entre os circenses desde a primeira metade do século XIX. Antes da estreia de seu circo remodelado na Mem de Sá, Floriano participou de um evento de 
caridade para arrecadar fundos para a manutenção do Centro Marítimo da cidade do Rio de Janeiro juntamente com "os melhores artistas dos circos brasileiros" (O PAIZ, 27/10/1921, p. 5). Este evento, denominado "Circo da Caridade”, consistia na reunião do Circo François, Circo Americano, Colyseu Dudú Circo, North American Circus, Democrata Circo, Circo Querillo8 e Pavilhão Floriano para a montagem de um espetáculo em comum (O PAIZ, 30/10/1921, p. 6).

As parcerias estabelecidas por Zeca Floriano evidenciam, mais uma vez, o quanto ele esteve envolvido intensamente com as produções circenses do período, tanto nacionais como internacionais, e, conforme tratamos anteriormente, o quanto possivelmente tenha aprendido e trocado saberes com os circenses, sendo, dessa maneira, uma figura de intersecção e mescla entre o campo das artes, do esporte, da ginástica e das produções corporais em geral.

A partir de 1924, Zeca mudou-se para cidade de Campina Grande, na Paraíba, e passou a empreender diversas ações no campo do circo, dos esportes e da Educação Física pelo Nordeste, a exemplo do encerramento das apresentações do Pavilhão em Recife, em maio de 1924, em que Zeca Floriano convidou as "Ligas Pernambucanas de Desportos Terrestres e Náuticas" e a "Associação de Cronistas Desportivos" (JORNAL PEQUENO, 31/o5/1924, p. 2) para prestigiarem os espetáculos. Esse fato evidencia ainda mais o quanto Zeca, em seu trânsito permanente entre as manifestações circenses, da ginástica, da Educação Física e dos esportes, assumia, produzia e proclamava intersecções, diálogos e misturas entre esses campos, não somente no Rio de Janeiro, mas também em outros Estados.

Possivelmente residindo em Pernambuco a partir de 1931, Zeca Floriano dirigiu em Recife, em 1933, uma "Escola de Cultura Física", também denominada "Escola de Cultura Floriano", composta por "todos os aparelhos necessários ao cultivo do físico do indivíduo: ringue, trapézios, barras, paralelas,

\footnotetext{
8 É possível que o circo denominado de "Querillo" seja, na realidade, o circo da família Queirolo, fundado em fins do século XIX e que chegou ao Brasil em 1917 (ANDRIOLI, 2007).
} 
etc." (JORNAL PEQUENO, 31/05/1933, p. 2). Além disso, Floriano novamente trabalhou de forma constante no picadeiro de outros circos. Ainda no ano de 1926, lutou com "Pocarelli e Antonio Ferreira" no Circo Strighiny (JORNAL PEQUENO, 21/o5/1926, p. 3) e, em 1931, pelejou com o urso "Kluka", no circo Stevanovich (JORNAL PEQUENO, 16/12/1931, p. 3). No ano de 1933, enfrentou o lutador “João Baldi” no picadeiro do Circo Nerino, sendo que para essa segunda luta, o circo providenciou que o ringue fosse armado no centro do picadeiro numa altura suficiente para que os espectadores pudessem apreciar a pugna dos seus lugares (JORNAL PEQUENO, 19/01/1933, p. 4).

Juntamente com suas exibições em outros circos, o atleta também montou seu Pavilhão em Recife, promovendo exibições de disputas de luta livre e boxe inglês dirigidas por ele mesmo (JORNAL PEQUENO, 29/o9/1933). Dessa estreia do circo em Recife, em setembro de 1933, vale mencionar que a nota de divulgação do primeiro espetáculo referenciou Floriano como "conhecido atleta e professor de ginástica", menção esta devido à popular carreira de Floriano no campo dos esportes e, possivelmente, por sua atuação como professor em sua Escola de Cultura Física sediada na capital pernambucana (JORNAL PEQUENO, 30/o9/1933, p. 4).

No ano de 1937, Zeca Floriano retornou para o Rio de Janeiro levando suas atrações circenses e uma programação teatral mais amplificada em seus espetáculos (GAZETA DE NOTÍCIAS, 12/05/1937). A partir desse período, encontramos poucas informações referentes à sua trajetória e ações no campo do circo, da ginástica e de outras práticas corporais ligadas ao esporte e à Educação Física. Apesar disso, em 21 de abril de 1939, a Gazeta de Notícias publicou uma nota intitulada "O Novo Instrutor de Cultura Física da Prefeitura", na qual informa que, por meio de um despacho assinado pelo prefeito da cidade, José Floriano Peixoto foi contratado para exercer as funções de "Instrutor Chefe de Educação Física da Diretoria de Segurança" (p. 8). Nesta função, Floriano permaneceu até pelo menos o ano de 1955 (CORREIO DA MANHÃ, 28/o1/1955) e, conforme o Diário Carioca de cinco de agosto de 1952 
(p. 12), Zeca "até há poucos anos atrás, de cabelos brancos, ainda fazia exibições de seu invejável físico e de sua extraordinária força muscular”, consideração esta que indica que, possivelmente, até o final dos anos de 1940 Floriano ainda estava na ativa também com demonstrações no âmbito da ginástica, dos esportes e do espetáculo.

Ainda, num pequeno texto de cunho biográfico sobre José Floriano, publicado na edição de 28 de dezembro de 1956 no periódico Imprensa Popular (p. 7), o autor, depois de entrevistar Zeca, conclui a matéria informando que “mais uma vez Zé Floriano Peixoto aí está, disposto a auxiliar os jovens, a dar seu esforço e experiência para o incremento da educação física, do halterofilismo, pronto a transmitir aos atletas de hoje os segredos e peculiaridades dos velhos alteres que tantas vezes levantou”.

Do ano de 1956 em diante, encontramos uma quantidade ainda menor de fontes a respeito de suas atividades, sendo, em sua maioria, sucintas matérias que tratam do auge de sua trajetória no contexto da ginástica, dos esportes, da Educação Física e circo. Quanto ao falecimento de Zeca Floriano, não conseguimos localizar registros que tratem dessa informação, mas é possível que tenha ocorrido entre o período de agosto de 1966 a novembro de 1972, pois foi publicada uma nota de felicitação de seu aniversário em 05 de agosto de 1966 (CORREIO DA MANHÃ, 05/08/1966) e, posteriormente, um resumido artigo, em 11 de novembro de 1972, sobre a biografia do Marechal Floriano Peixoto, pai de Zeca, que informa que todos os filhos homens do expresidente da república já haviam falecido (CORREIO DA MANHÃ, 11/11/1972).

\section{ZECA FLORIANO: ENTRE MISTURAS E DIÁLOGOS}

Conforme buscamos apresentar, Zeca Floriano em seu extenso e permanente trânsito entre as manifestações circenses, da educação do corpo e dos esportes, assumia, divulgava e proclamava intersecções, diálogos e misturas 
entre esses campos, não somente no Rio de Janeiro, mas também em outros estados.

Tendo, portanto, sua formação inicial em um Colégio Militar e atuado intensamente como professor de ginástica em diversos clubes, centros e escolas de cultura física, parte de sua instrução residiu no campo das práticas ginásticas e corporais institucionalizadas, de cunho higienista, militar e cientificista em voga no período. Simultaneamente, e com mesmo empenho e intensidade, Floriano também se dedicou às artes circenses, mesmo que suas ações e representações corporais fossem criticadas e desqualificadas por aqueles que atuavam com uma educação do corpo sedimentada no período pela terminologia e amplo conceito de ginástica em diversas instituições médicas, escolares, militares e associativas.

Nesse sentido, evidenciamos também o quanto os saberes dos circenses estiveram alicerçando e, em certa medida, promovendo estas misturas e diálogos entre tais campos, e que a profícua e multifacetada trajetória do sportsman, artista, empresário e professor de ginástica Zeca Floriano teve no circo e nos circenses uma "escola".

Assim, Zeca foi simultaneamente ginasta, atleta, professor, empresário e artista circense, e promovia a fusão dos saberes do circo e da ginástica e os exteriorizava em suas aulas, espetáculos, exibições diversas, centros de cultura física etc. Ou seja, vivia e atuava igualitariamente no campo do circo e da ginástica, carregando tanto a responsabilidade da formação física da juventude, respaldada pelo discurso médico higienista do período, quanto de exímio artista, empresário circense, atleta e aclamado sportsman.

Posto isso, não foi por acaso que Floriano ofereceu em sua Escola de Educação Física aulas de ginástica, Acrobacia, Atletismo e lutas, em 1909; ofertava o "higiênico esporte de ginástica e outros exercícios" (O PAIZ, 20/06/1907, p. 5) no Esporte Clube José Floriano, em 1911, e inaugurou as aulas de ginástica do Centro Cívico Sete de Setembro juntamente com a companhia do Circo Spinelli e em seu picadeiro, em 1913; e que as instituições 
que fundou, dirigiu e lecionou, públicas e privadas, a exemplo da Escola Atlética Modelo José Floriano, possuíam uma "higiênica sala" (O PAIZ, 27/01/1915, p. 6) e contavam com "ringue, trapézio, barras, paralelas" (JORNAL PEQUENO, 09/01/1933, p. 2). Em outros termos, o que queremos explicitar com essas considerações é que tanto nas aulas de acrobacia e ginástica ministradas por Floriano, que muito possivelmente continham exercícios similares às ações corporais dos artistas de circo, como por meio da utilização de trapézios e paralelas, a incorporação e aplicação dos saberes, técnicas e práticas circenses por parte de Zeca estiveram presentes na sua atuação como ginasta, atleta e, principalmente, como professor, mesmo que revestidas da intencionalidade de desenvolver o "físico dos filhos do nosso Brasil" (O PAIZ, 27/01/1915, p. 6) dentro de preceitos científicos, perspectivas higienistas e de controle e retidão dos corpos vigentes no período que condenavam as práticas circenses.

Ainda, reforçando essa perspectiva do quanto os saberes e práticas circenses alicerçaram o trabalho de Floriano em seus estabelecimentos de ensino, exibições atléticas e esportivas e como professor de ginástica, é importante ressaltar que, para além do fato de Zeca ter fundado e dirigido seu próprio circo, ele trabalhou intensamente como artista circense. Desde feitos de coragem e lutas espetaculares, como sua entrada na jaula do leão Marrusko ou a luta com o urso Kluka, ou mesmo a peleja com o lutador alemão Scharmann ou com o lutador João Baldi, até sua atuação como equilibrista e acrobata no Trio Floriano, podemos considerar que Zeca estava marcado pelo circo e pelo espetáculo, que o circo estava inscrito em seu corpo e, consequentemente, em suas diversas apresentações artísticas, exibições atléticas e ações educativas nas instituições que dirigiu e lecionou.

Enfim, por meio desta abordagem de alguns percursos de Zeca Floriano no âmbito da ginástica, do esporte, do circo e da Educação Física no início do século $\mathrm{XX}$, é possível compreender o quanto as práticas corporais circenses e às ligadas à ginástica, aos esportes e à educação do corpo estiveram em permanente mistura e diálogo, entrelaçadas e conjugadas por intermédio da 
espetacularização das mesmas, do picadeiro como espaço que as fundia, da similaridade dos aparelhos utilizados nas aulas de ginástica e da semelhança das ações corporais que assumiam. Com isso, evidencia-se a necessidade de pensar a ginástica no decorrer do século XIX e início do XX de forma plural, bem como o quanto os saberes circenses referentes à produção de seus espetáculos, sobre o corpo e a ginástica foram presentes e significativos para a constituição da educação do corpo gestada no período abordado.

\section{REFERENCIAS}

AMOROS, Francisco. Nauveau Manuel d'éducation physique, gymnastique et morale. Paris: Tome premier, 1838.

ANDRIOLI, Luiz. O Circo e a Cidade: histórias do grupo circense Queirolo em Curitiba. Curitiba: edição do autor, 2007.

AVANZI, Roger; TAMAOKI, Verônica. Circo Nerino. São Paulo: Pindorama Circus-Códex, 2004.

CERTEAU, Michel de. A escrita da história. Rio de Janeiro: Forense Universitária, 2010.

CORREIO DA MANHÃ. Rio de Janeiro (RJ), 28/01/1955, 05/08/1966, 11/11/1972.

CORREIO PAULISTANO. São Paulo (SP), 04/04/1909, 09/11/1913, 14/02/1916, 01/08/16, 10/01/1920.

DIÁRIO CARIOCA. Rio de Janeiro (RJ), 05/08/1952.

GAZETA DE NOTÍCIAS. Rio de Janeiro (RJ), 24/10/1904, 29/09/1905, 21/04/1906, 16/01/1909, 29/09/1909, 26/05/1911, 24/01/15, 12/05/1937, 21/04/1939.

GOELLNER, Silvana. O Método Francês e a educação física no Brasil: da caserna à escola. 1992. 214 f. Dissertação (Mestrado em Educação Física) Escola Superior de Educação Física, Universidade Federal do Rio Grande do Sul, Porto Alegre, 1992.

GÓIS JUNIOR, Edivaldo. Ginástica, higiene e eugenia no projeto de nação 
brasileira: Rio de Janeiro século XIX e início do XX. Revista Movimento, UFRGS, Porto Alegre, v. 19, n. 01, p. 139-159, jan./mar. 2013.

GÓIS JUNIOR, Edivaldo; HAUFFE, Mirian. Kormann. A educação física e o funâmbulo: entre a arte circense e a ciência (século XIX e início do século XX). Revista Brasileira de Ciências do Esporte, Florianópolis, v. 36, n. 2, p. 547-559, abril/jun. 2014.

GONDRA, José. Medicina, higiene e educação escolar. In: LOPES, Elaine Marta Teixeira; FARIA FILHO, Luciano Mendes de; VEIGA, Cynthia Greive (org.). 500 anos de Educação no Brasil. Belo Horizonte: Autêntica, 2000, p. 88109.

HIGGINS, Arthur. Compendio de Gymnastica Escolar Methodo SuecoBelga-Brasileiro. Rio de Janeiro: Typografia do Jornal do Commercio, 1934.

IMPRENSA POPULAR. Rio de Janeiro (RJ), 28/12/1956.

JORNAL PEQUENO. Pernambuco (PE), 31/o5/1924 21/05/1926, 16/12/1931, 09/01/1933, 19/01/1933, 31/05/1933, 29/09/1933, 30/09/1933.

LOPES, Daniel de Carvalho Lopes; SILVA, Erminia. Pirâmides da memória: Mehdi Ben M' Barek e suas histórias circenses. Campinas, 17 fev. 2019.

Disponível em: http://www.circonteudo.com/fabricante-historia/piramides-damemoria-mehdi-ben-m-barek-e-suas-historias-circenses/. Acesso em: o5 jun. 2019 .

LOPES, Daniel de Carvalho. A contemporaneidade da produção do Circo Chiarini no Brasil de 1869 a 1872. 2015. 84 f. Dissertação (Mestrado em Artes Cênicas) - Programa de Pós-Graduação em Artes, Instituto de Artes, Universidade Estadual Paulista "Júlio de Mesquita Filho"/Unesp. São Paulo, 2015 .

LOPES, Daniel de Carvalho; SILVA, Erminia. Circos e palhaços no Rio de Janeiro: Império. Rio de Janeiro: Grupo Off-Sina, 2015.

MELO, Victor Andrade de. Dicionário histórico do esporte no Brasil do século XIX ao início do século XX. Campinas: Autores Associados, 2007 a.

MELO, Victor Andrade de. Mulheres em movimento: a presença feminina nos primórdios do esporte na cidade do Rio de Janeiro (até 1910). Revista

Brasileira de História, São Paulo, v. 27, n. 54, p. 127-152, 2007 b.

MELO, Victor Andrade de. O corpo nas searas tupiniquins - panorama histórico. In: PRIORE, Mary Del; AMANTINO, Márcia (org.). História do corpo no 
Brasil. São Paulo: Editora Unesp, 2011. p. 506-529.

MELO, Victor Andrade de; PERES, Fábio de Faria. A gymnastica no tempo do Império. Rio de Janeiro: 7 Letras, 2014.

NASCIMENTO, Douglas. O leão e o filho do presidente. São Paulo, 28 set. 2015. Disponível em: http://www.saopauloantiga.com.br/o-leao-e-o-filho-dopresidente/. Acesso em: 05 jun. 2019.

O PAIZ. Rio de Janeiro (RJ), 21/04/1905, 23/04/1911, 29/05/1907, 20/06/1907, 07/09/1911, 16/09/1911, 18/09/1911, 01/01/1913, 23/12/1913, 26/12/1913, 28/01/1914, 15/o5/1914, 27/01/1915, 04/05/1915, 30/11/1917, 01/12/1917, 27/07/1921, 31/o7/1921, 09/08/1921, 27/10/1921, 30/10/1921, $17 / 11 / 1921$.

RENEVEY, Monica J. (org.). Le grand livre du cirque. Genebra: EditoService Bibliothèque des Arts, 1977. 2 v.

REVISTA A CIGARRA. Rio de Janeiro (RJ), o1 agosto de 1953, número 233.

REVISTA DE THEATRO E SPORT. Rio de Janeiro (RJ), 09/07/1921, ano VIII, n. 348 .

RIBEIRO, Flávia. Tradição carioca. Rio de Janeiro: IstoÉ, n. 15, ano 6, p. 2734, março de 2015 .

ROMÃO, Anna Luiza Ferreira. Entre escolas, clubs e sociedades: as gymnasticas tecidas por professores no Rio de Janeiro (1850-1900). 2016. $199 \mathrm{f}$. Dissertação (Mestrado em Educação) - Programa de Pós-Graduação em Educação, Faculdade de Educação, Universidade Federal de Minas Gerais/UFMG, Belo Horizonte, 2016.

SANT'ANNA, Denise Bernuzzi de. É possível realizar uma história do corpo? In: SOARES, Carmen Lúcia. Corpo e história. Campinas: Autores Associados, 2011. p. $45-54$.

\section{SILVA, Daniel Marques da. O palhaço negro que dançou a chula para o} Marechal de Ferro: Benjamim de Oliveira e a consolidação do circo-teatro no Brasil - mecanismos e estratégias artísticas como forma de integração social na Belle Époque carioca. 2004. 182 f. Tese (Doutorado em Teatro) - Centro de Letras e Artes, Universidade Federal do Rio de Janeiro/UFRJ, Rio de Janeiro, 2004.

SILVA, Erminia. Circo-teatro: Benjamim de Oliveira e a teatralidade circense no Brasil. São Paulo: Altana, 2007. 
SILVA, Erminia. Respeitável público... O circo em cena. Rio de Janeiro: Funarte, 2009.

SOARES, Carmem Lúcia. Imagens da educação no corpo: estudo a partir da ginástica francesa no século XIX. 3. ed. Campinas: Autores Associados, 2005.

SOARES, Carmen Lúcia. Da arte e da ciência de movimentar-se: primeiros momentos da ginástica no Brasil. In: PRIORI, Mary del; MELO, Victor Andrade (org.). História do esporte no Brasil: do império aos dias atuais. São Paulo: Editora Unesp, 2009. p. 133-175.

SOARES, Carmen Lúcia. Educação Física: raízes européias e Brasil. Campinas: Autores Associados, 2001.

VIGARELLO, Georges. A invenção da ginástica no século XIX: movimentos novos, corpos novos. Revista Brasileira de Ciências do Esporte, Florianópolis, v. 25, n. 1, p. 09-20, 2003.

DANIEL DE CARVALHO LOPES é pesquisador em nível de doutorado na Faculdade de Educação da Universidade de São Paulo, vinculado ao departamento de Cultura, Organização e Educação. Membro do Grupo de Pesquisa em Circo (CIRCUS) da Faculdade de Educação Física da Unicamp e do Grupo de Estudos e Pesquisas em Gesto, Expressão e Educação (GEPGEE) da Faculdade de Educação da USP.

E-mail: territio@gmail.com

(b) http://orcid.org/0000-0002-2137-2060

MÔNICA CALDAS EHRENBERG é professora da Faculdade de Educação da Universidade de São Paulo, vinculada ao departamento de Metodologia de Ensino e Educação Comparada, além de professora efetiva da linha de Pós Graduação em Cultura, Organização e Educação. Coordenadora do Grupo de Estudos e Pesquisas em Gesto, Expressão e Educação (GEPGEE) da Faculdade de Educação da USP.

E-mail: monica.ce@usp.br

(i) http://orcid.org/0000-0002-2445-1362 
Revista História da Educação (Online), 2020, v. 24: e94488 DOI: http://doi.org/10.1590/2236-3459/94488
e-ISSN: $2236-3459$ http://seer.ufrgs.br/asphe

\footnotetext{
(c) (P)

Revista História da Educação - RHE

Associação Sul-Rio-Grandense de Pesquisadores em História da Educação - Asphe

Artigo de acesso aberto distribuído nos termos de licença Creative Commons.
} 